\title{
Mathematics Education for Engineering Technology Students - A Bridge Too Far?
}

\author{
http://dx.doi.org/10.3991/ijep.v3iS2.2443 \\ Noraishiyah Abdullah \\ The University of Manchester, United Kingdom \\ Universiti Kuala Lumpur, Malaysia
}

\begin{abstract}
Trying to decide what is best suited for someone or something is an ever enduring task let alone trying to prepare students with the right engineering mind. So 'how do you build an engineer?' if that is the right word. What is the right ingredient? Mathematics has been said as the most important foundation in engineers' life. Curriculum has been developed and reviewed over the years to meet this target. This work explores how much or lack of it has the curriculum prepares the future technologist to face the world of engineering technology as far as mathematics is concerned. Analysis of mathematics lectures, interviews of engineering technologist students and engineering technology subject lecturer is undertaken. Understand what each contributes help in understanding the picture that the current education is painting. Based on the theory of learning, APOS theory helps in explaining how students bridge their knowledge of mathematics when it comes to solving engineering technology problems. The question is, is it a bridge too far?
\end{abstract}

Index Terms-APOS Theory; engineering technologists; engineering technology; mathematics

\section{INTRODUCTION}

This research is conducted in the interest to explore the pedagogical strategy practices by the teacher in her effort to teach the topic of differential equation. Differential equation is one of the many topics in mathematics that is seen as the heart of modern application mathematics in natural phenomena.("Teacher Package : Differential Equation," 2007). In the past twenty years Malaysia has moved from an agricultural towards a technology based economy. Tertiary education institutions therefore have a vital role to play supporting knowledge-driven economic growth strategies and poverty reduction by training a qualified and adaptable labour force, generating new knowledge and building capacity to access existing stores of global knowledge and to adapt that knowledge to local use (World Bank, 1994, 2002). This change has resulted in a demand for a more technically trained work force. Universities are, therefore, responsible for training and producing more graduates that will spearhead the drive towards a technology based economy and in order to train such students in engineering we will need to educate them in mathematics. Teaching mathematics to these engineering students poses particularly difficult challenge with teachers expecting students to reach a high level of proficiency in mathematics as they progress to learning more demanding topics in engineering.
In addition, too much is taken for granted when it comes to transferring knowledge especially in mathematics. What is learned in one context cannot be assumed can be easily transferred or applied into another context or situation (Brown, Collins, \& Duguid, 1989). This research will focus on the teaching, learning, application and transfer of important mathematical concepts in first year of undergraduates studies focused on student's learning at the Universiti Kuala Lumpur using case study methodology. The case involves engineering students who are registered for mathematics as one of the compulsory subjects for their engineering programs. This research is important as it will inform of good practice in the teaching and learning of the subject. It will also add value to existing research and research in undergraduate mathematics education community developing understanding of how theoretical tools might inform our understanding of issues in relation to learning and transfer of mathematical concepts. At the Universiti Kuala Lumpur, mathematics is taught to all first year engineering students by lecturers from the mathematics unit. My research will focus on the topic of Differential Equations, one particular topic of mathematics that is taught to all engineering students. The main objectives of the teaching are that students will be able to recognize different types of differential equations and how to solve them. Students are the expected to be able to apply their knowledge and understanding in other engineering topics such as Control Theory, Robotics and some electronic related subjects making it one of the most important tools for students to master. From my fourteen years experience teaching at the university, I know that the teaching approach used is mainly procedural with analytical solution methods developed as procedures which are applied to algebraic families of solution functions.

\section{MATERIAL AND METHODS}

\section{A. Literature Review}

A theory of learning could help us understand the learning process by providing an explanation of phenomena. This can be observed in students trying to construct their understanding of mathematical concepts. It can also suggest directions for pedagogy that can help in this learning process (E. Dubinsky \& McDonald, 2001). Piaget suggests that knowledge is actively constructed by each individual. Through shifting, knowledge is derived from the action which the individual performs leading to a constructed abstraction of the action process (Piaget, 1970).This is agreed by Cobb, Yakel \& Wood (1992) who say that learning as active construction implies that students build on and modify their current ways of mathe- 
matical knowing. This modification is personal and as such may vary from one individual to another. It is difficult to determine what stimulates the changes. Piaget says it depends on the individual learner. Piaget believes that children build their own cognitive tools, to them knowledge and the world are both constructed and constantly reconstructed through personal experience (Ackermann, 2001). So to explore their thinking is to explore their personal experience.

This leads to a question about the nature of mathematical knowledge? Students can understand in two different ways: either how to apply mathematical procedures (instrumental) or mathematical structure and interrelationship (relational). Can a procedure that has been memorized but not understood be considered as mathematical knowledge? Resnick, (1989), Romberg \& Carpenter (1986), Schoenfeld (1992) believe that all mathematical knowledge is relevant as Schoenfeld states in his book 'One's mathematical knowledge is the set of mathematical facts and procedures one can reliably and correctly use'. Being able to use facts, formulae and procedures is indeed an important component of mathematics even though students who are good at memorizing procedures are not necessarily understand the underlying ideas. Students who learn rules without reasons rely heavily on memory. Skemp (1976) categorized them as instrumental understanding as opposed to relational understanding. Gray \& Tall, (1994) suggest that all mathematics activities may be conceived initially by instrumental level but a reliance on remembering leads to an overburdening of the memory as more and more rules and procedures are encountered.

Skemp (1976) pointed out that many mathematics teachers are instrumental thinkers and their teaching tends to focus on algorithms and procedures. This has implications for students' understanding. Relational thinkers are able to condense knowledge within a schema and use it flexibly where as instrumental thinkers concentrate on applying one or more learned procedures until the solution is reached. Since schemas are cognitive construction derived from personal experience they might be expected to vary from one individual to another. Studies in the past by McGowan (1988) reveal that there exists a wide spectrum of schemas even amongst students who had been historically poor at mathematics. Her results suggest that success in the subject is a result of incorporating new information into an existing schema that is stable. Those students who progressed least showed clear signs of not having a stable schema or could hardly be considered to be a schema at all, more simply a collection of unrelated procedures and facts. This leads to the study on how do students construct schema, what tools could be used to help researcher learn about students construction of mathematical knowledge. Development of theory in mathematics education is an attempt to understand how mathematics can be learned and what educational activities can do to help in the learning (E. Dubinsky \& McDonald, 2001).

APOS(Action, Process, Object, Schema) Theory in particular has been used by many researchers to investigate the understanding of mathematics ranging from topic in elementary level such as number fraction(Cottrill et al., 1996; Herman et al., 2004; Kirk Weller, Arnon, \& Dubinsky, 2009) number concept(Gray, Pinto, Pitta, \& Tall, 1999) to tertiary level like concept of limit(Cottrill, et al., 1996) function(K Weller et al., 2003) and linear alge-
bra(De Vries \& Arnon, 2004)In addition to that, Bennett in his project called REESE uses APOS theory to track transfer of ideas from mathematics to physics to engineering (Bennett, 2009). APOS theory can be used directly in the analysis of data by researcher. In very fine grain analyses, the researcher can compare the success or failure of students on a mathematical task with the specific mental constructions they may or may not have made. APOS theory has one characteristic that is called genetic decomposition, in which it can help determine a specific construct at any of each level. However there is no research to investigate the understanding of differential equations has been conducted using the framework of APOS theory and it has not been used to help understand problems of transfer. So I will use APOS Theory to make sense of understanding of differential equations in mathematics and applying the understanding to engineering problems.

Previous research in differential equations however has concentrated on experimenting pedagogical approach through the use of Realistic Mathematical Education (RME). Rasmussen states that for new areas of interest such as differential equations, mapping out students' understandings of important mathematical ideas can be an important part of curricular and instructional design that seeks to refine and build on students' ways of thinking(C. Rasmussen, 2001). His other research reveals that the use of Realistic Mathematics Education (RME) to locate a starting point for an instructional sequence for first-order differential equation might help students to experience creation of mathematical ideas. C. L. Rasmussen \& King (2000) have done much research in developing improvement in pedagogical approach in particular in the teaching of differential equations. Rasmussen and Marrongelle, (2006) suggests that students have problem understanding and interpreting the qualitative representation of solution of differential equations. Unfortunately researchers tend to agree that experiment on intervention of pedagogical seems to give positive effect on students understanding but the effect do not last very long as teachers tend to revert to traditional methods(C. Rasmussen, 2001). Not much research has been undertaken on how to improve the traditional way of teaching mathematics even though there is a finding saying that students prefer procedural approach to conceptual approach (Johann Engelbrecht, Christer Bergsten, \& Kågesten, 2009).

A considerable number of research has contributed to the understanding of how to approach the teaching of differential equations but there is still not much research undertaken that dealt with the transfer of knowledge of differential equations in other field such as engineering. Transfer is often defined as the ability to apply what has been learned in one context to a new context (Byrnes, 1996). Rebello et al (2005) describes transfer as dynamic construction of association between the two contexts mediated by several factors and Newmann,(1989) suggests that graduated prompting to be effective way to assess transfer and the factors that control it. Previous research in differential equations did not seem to accommodate the issue of transfer of differential equations into other context other than mathematics. Part of this study will focus on how students apply their understanding of differential equations when solving engineering problems.

Particularly in Malaysia not much research has been done on how engineering students learn and apply their knowledge of mathematics during their undergraduate 
studies. From the above literature I can see that there is definitely a gap in the literature that requires a study to be conducted to explore students' understanding in particular towards the teaching, learning and applying of differential equations both in mathematics and in engineering situations. This research will contribute to these studies.

\section{B. Theoretical Framework}

The identification of the nature of students' understanding and its association with the way in which students construct the concept of Differential Equation is of great importance on the way to the development and implementation of good instructional strategies. APOS Theory provides a research tool that has been successfully used in other areas of mathematics such as abstract algebra and calculus, for similar purposes. I will employ the APOS theory in analyzing the data gathered during the interview as well as evaluating the exam answer script of the interviewee and the videoed lectures given on this topic. APOS theory says that students build concepts through a standard set of steps of Action-Process-Object-Schema. (E. Dubinsky \& McDonald, 2001)With a clear definition on each step taken we can identify the student level of understanding. At action level students are expected to be able to carry out rote procedures bound to specific representations. At process level we can see that students are able to see the process as a whole, they can use multiple representation, they can reverse the process, or compose with other processes and at object level students are able to reify the process into an object and they can discuss properties of the other object or collections of examples of the process.

With this tool we are able to understand how students develop their understanding of differential equations in relation to their learning experience and how they transfer this knowledge to solve engineering situations. Bennett(2009) explains, by taking examples on learning the concept of function shows how the APOS theory can be used to differentiate the level of students' understanding and progress in building a concept of mathematics. Bennett (2009) exemplifies the use of APOS theory in helping us distinguish students' level in building their concept of function and integration. I believe the same could be done for other topics in mathematics in particular Differential Equations.

With the classification of activities for each level we are able to explore students' understanding or difficulties in achieving that particular level. Not only that we can determine the students' level in understanding the concept but also we can map out their difficulties that they faced at each level based on the APOS theory

\section{Research Questions}

This research will investigate the learning of mathematics of the first year engineering students. In order to do that I am addressing the following research questions:

How do first year engineering students develop: (a) their understanding of differential equations in relation to the teaching they receive, and (b) their ability to use this understanding to solve problems in engineering situations?

\section{Research Method}

This research has been conducted using a case study approach. The case studies focus on five or six individual students from the first year engineering program who registered for mathematics. The studies also focus on the lecturers who teach mathematics for this group. Data collected involves in-depth interviews, focus groups and document analysis. Student participants have been chosen based on their mathematics result from the previous semester examination. 6 participants that represent high, medium and low attainment in mathematics were chosen to participate in the in-depth interviews. The learning activities of these 6 participants as they are learning the topic of differential equations during mathematics as well as engineering lessons were recorded. I expect to conduct case studies of up to 6 individuals with interesting response patterns. Case studies will provide rich data that will enable in-depth investigation, analysis and understanding.

All lectures in mathematics and engineering subjects that deal with the topics of differential equations will be video recorded for analysis. Based on which 2 focus group sessions will be conducted. In addition to the above activities, documents such as lecture notes, tutorial questions, and student answer scripts will be collected and analyzed in order to support the other findings. The data gathered from the interview, focus group and document analysis will help in triangulating the result. This triangulation seeks convergence, corroboration, and correspondence of results from the different methods (Greene \& Caracelli, 1989). Data gathered from other sources such as the participant's tutorials, examination answer scripts, video of lectures will also help in complementing the findings from major sources (Greene \& McClintock, 1985).

\section{E. Sample}

A purposive sampling was employed in this research. The University Kuala Lumpur offers 6 different bachelor degree programs in engineering ranging from mechatronic, industrial automation and robotic, welding quality inspection, machine tools manufacturing, air-conditioning and refrigeration and automotive. There are two intakes of students per academic year. The intakes are in January and July. The number of students for each intake is approximately $150-200$ students. Mathematics is a common subject to all engineering students. All engineering students are required to register for compulsory mathematics namely M1, M2 and M3. Lectures are normally divided into two big groups. I chose participants from Industrial Automation and Robotic Technology and Air Conditioning and Industrial Refrigeration program who are in their second semester, as students from this program have used the topic of Differential Equations quite extensively. Students from this program attend mathematics lectures together with all the other students but they then are placed into tutorial groups according to their program. Mathematics lecturer responsible to teach this group is automatically selected for interview with their prior consent.

\section{RESULTS AND DISCUSSIONS}

For the purpose of this paper I will only discuss the outcome form one case. This outcome will be the basis of all the future discussion of the outcome of this research activity. I will discuss about the genetic decomposition of the topic of differential equation the way the teacher sees it and how the student receives it. The centre of the discussion will be around 'what is differential equation?'. 
How the teacher plans her lesson based on the genetic decomposition of differential equation.

What is genetic decomposition?

As APOS Theory puts it, genetic decomposition is a theoretical analysis that proposes a set of mental construction that student might make in order to understand the mathematical concept being studied (E. Dubinsky \& McDonald, 2001). In the case of the concept of differential equation, the analysis from the teacher's interview proposes that student should work on very explicit examples to construct an action conception of differential equation which will result that she/he can interiorize these actions to form processes. The student encapsulates the process of solving differential equations to think of differential equation as object. She then designed her pedagogical strategies to help students make these constructions and relate them to the conception of differential equation.

What is her genetic decomposition of differential equation?

The teacher was interviewed before her lecture on the topic of differential equation, below is part of the transcript from that interview.

$I$ : what is differential equation...

$E$ : yes, right, I will tell them what is differential equations then I will give them err example what is differential equations I mean like any of the equation that involved derivative we will call it differential equations and I am going to explain to them if we want to solve differential equations what does it mean.. what are we going to find then through the introduction then I'm going to start lectures and explain to them that we got many types of differential equations, we got first order, second order and we go to classification of the differential equations why this is called first order why this is second order what is meant by dependent variable, independent variable.....

When analyzing this response, the fact that she talks about the definition of differential equation and then she jumps into solving differential equation suggests that she is going for action conception (Ed Dubinsky \& Harel, 1992). From her response it is not clear where the element of the APOS theory (action, process, object, schema) are and how she is preparing her students to arrive at all the four levels of conceptions of differential equation. In order to decide, we next investigate on her lecture as she implements her plan into action. During her first lecture she poses a lot of conceptual questions in order to get her students engage in the topic. For example,

\section{$E$ : 'what is a differential equation?'.}

This question in itself looks new to the students but in actual fact this question contains a lot more than it seems. It is not clear what the expectation of the teacher is at this point but that question gives the teacher a chance pull in a lot of different schemas into the mind of the students even before they started further the topic of differential equation, which I will explain later. After waiting a short while it has become clearer to what is the expectation of the teacher is as seen below.

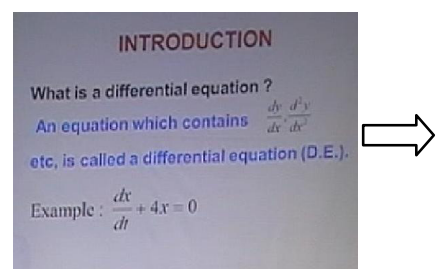

Figure 1a

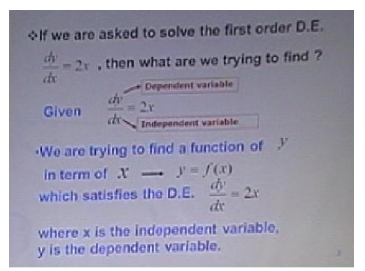

Figure 1b
She explains the definition symbolically by using the symbol of the derivative instead of the meaning of the derivative which is the rate of change of one variable as related to the change in the other variable, then only she tries to link for further definition by asking the immediate question as seen in Figure 1b. Her definition as given in Figure $1 \mathrm{a}$ is generally the minimum definition that one could give to describe differential equation. Based on her explanation so far, I will try to see what the definition student conceives.

What is the student understanding of differential equation?

I would like to share here the answer from three students who participate in the research study.

$I$ : so to you, what is actually differential equations $M$ : ahah.. differential equation ermm is an equation then

we differentiate it with to , I think to have ,.. to find ermm to find err the ..how to say...

I :..............what is differential equations..what does it

deals with

$S$ : for me

I : yes to you ... what does it mean to you.. what did you

learn about it, where does it come from

$S$ : oo ..differential equation is like..when you investigate

the change in one variable with respect to other variable

like $x$ and $y$ or with respect to time or distance for example like rate, related rate, rate of change of something when we refer to something..like that

$I:$........ what is differential equations if you can recall

$H$ : ermm DE, differential equations, I think, I remember

there's law about DE, is there a law?

Clearly $\mathrm{M}$ and $\mathrm{H}$ has limited memory on the definition of differential equation at this stage as compared to S how has managed to states his understanding of differential equation if evaluated through the lenses of APOS theory, could be said to have a level of object conception. Further probe into $\mathrm{M}$ and $\mathrm{H}$ reveals that they display what could be said by APOS theory as someone having an action conception of differential equation. All the three students display a fluency in algebraic operation nevertheless has 
very limited understanding on the concept of differential equation.

APOS theory suggests that at this stage the genetic decomposition has to be further refined to help students to be able to have deeper understanding on the topic.

\section{CONCLUSION}

The initial analysis of the data collected show that the teacher need to refine her genetic decomposition with more detail focus on the pedagogical strategy to enable students to develop deeper conceptual understanding on differential equation, so that students could perform pass the action and process level as suggested by APOS Theory. Better strategies will help students move through the stages. APOS Theory has not able to clearly guide researcher to identify specifically the level of conception of students. It is more of a framework of how people could learn mathematics and not a diagnostic tool.

\section{A. Contribution to knowledge}

This study is purposive to the development and improvement on the teaching practice of the university. The problem might be local but the issues are global. There was no research conducted using APOS Theory to explore students' learning of differential equations and how they use their understanding to solve engineering situations. Findings from this study will add value to research conducted regarding differential equations. It will also inform the mathematics education community on how mathematics is being transferred to engineering.

Detailed analysis of the course and the students' answers' to the questions in the interview will shed light into their understanding and will also allow us to make didactical suggestions to improve the design of the course and propose other activities for the students. The study will also provide a methodological contribution to knowledge. The development of the genetic decomposition of differential equations is a contribution to the research field for further improvement and refining of learning outcomes of differential equations. This research provides the basis for further development in research using APOS Theory Using APOS theory to analyze students' learning of mathematical concept has yet to be applied in Malaysia, APOS theory has been used as tool to understand students understanding as concept in other area of mathematics but not differential equations. This will add to the collection of RUME (Research in Undergraduate mathematics Education) and the working group of APOS as established by RUME.

\section{REFERENCES}

[1] Ackermann, E. (2001). Piaget's Constructivism, Papert's Constructionism : What is the difference?

[2] Bennett, A. (2009). APOS Theory. Retrieved from web.phys.ksu.edu/current/seminar/f09/09-14-09-bennett.pdf.

[3] Brown, J. S., Collins, A., \& Duguid, P. (1989). Situated Cognition and the Culture of Learning Educational, Evaluation and Policy Analysis, 18(1), 32.

[4] Byrnes, J. P. (1996). Cognitive development and learning in instructional contexts. Boston, MA: Allyn and bacon.

[5] Cobb, P., Wood, T., \& Yackel, E. (1992). A constructivist alternative to the representational view of mind in mathematics education. Journal for Research in Mathematics Education, 23(1), 2-33. http://dx.doi.org/10.2307/749161
[6] Cottrill, J., Dubinsky, E., Nichols, D., Schwingendorf, K., Thomas, K., \& Vidakovic, D. (1996). Understanding the Limit Concept: Beginning with a Coordinated Process

[7] Schema. Journal of Mathematical Behavior, 15, 167-192.

[8] De Vries, D., \& Arnon, I. (2004). Solution - What does it mean? Helping Linear Algebra students develop the concept while improving research tools. Paper presented at the 28th Conference of the International Group for the Psychology of Mathematics Education.

[9] Dubinsky, E., \& Harel, G. (1992). The concept of function: Aspects of epistemology and pedagogy, (Vol. 25). Washington, DC: The Mathematical Association of America.

[10] Dubinsky, E., \& McDonald, M. A. (2001). APOS: A constructivist theory of learning in undergraduate mathematics education research', in Derek Holton, et al. (eds.), The Teaching and Learning of Mathematics at University Level. Dordrecht, Netherlands: Kluwer Academic Publishers.

[11] Gray, E., Pinto, M., Pitta, D., \& Tall, D. (1999). Knowledge construction and diverging thinking in elementary \& advanced mathematics Journal Educational Studies in Mathematics, 38(13), 111-133. http://dx.doi.org/10.1023/A:1003640204118

[12] Gray, E., \& Tall, D. (1994). Duality, ambiguity and flexibility: A proceptual view of simple arithmetic. Journal for Research in Mathematics Education, 25(2), 116-140. http://dx.doi.org/ 10.2307/749505

[13] Greene, J. C., \& Caracelli, V. J. (1989). Toward a Conceptual Framework for Mixed-Method Evaluation Designs. . Educational, Evaluation and Policy Analysis, 11(3), 255.

[14] Greene, J. C., \& McClintock, C. (1985). Triangulation in Evaluation: Design and Analysis Issues. Evaluation Review, 9, 523-549. http://dx.doi.org/10.1177/0193841X8500900501

[15] Herman, J., Ilucova, L., Kremsova, V., Pribyl, J., Ruppeldtova, J., Simpson, A., et al. (2004). Images of fraction as processes and images of fraction in processes. Paper presented at the 28th Conference of the International Group for the Psychology of Mathematics Education.

[16] Johann Engelbrecht, Christer Bergsten, \& Kågesten, O. (2009). Undergraduate students' preference for procedural to conceptual solutions to mathematical problems. International Journal of Mathematical Education in Science and Technology, 36(7), 701712. http://dx.doi.org/10.1080/00207390500271107

[17] Piaget, J. (1970). Genetic Epistemology. New York: Norton.

[18] Rasmussen, C. (2001). New direction in differential equation. A framework in interpreting students' understanding and difficulties. Journal of Mathematical Behavior, 20, 55-87. http://dx.doi.org/10.1016/S0732-3123(01)00062-1

[19] Rasmussen, C., \& Marrongelle, K. (2006). Pedagogical Content Tools: Integrating Student Reasoning and Mathematics in Instruction. 37(5): 388-420. Journal of Research In Mathematics Education, 37(5), 388-420.

[20] Rasmussen, C. L., \& King, K. D. (2000). Locating starting points in differential equations : a realistic mathematics education approach. International Journal of Mathematical Education in Science and Technology, 31(2), 161-172. http://dx.doi.org/10.1080/ $\underline{002073900287219}$

[21] Resnick, L. B. (1989). Knowing, learning and instruction. Hillsdale, NJ: Lawrence Elrbaum Associates.

[22] Romberg, T. A., \& Carpenter, T. C. (1986). Research on teaching and learning mathematics: Two disciplines of scientific injury. . In M. C. Wittrock (Ed.), Handbook of research on teaching (3rd ed., pp. 850-873). New York: Macmillan.

[23] Schoenfeld, A. H. (1992). Learning to think mathematically: problem solving, metacognition, and sense making in mathematics. . In E. D.A. Grouws (Ed.), Handbook of Research on Mathematics Teaching (pp. 334-370). New York: Mac Millan Publishing.

[24] Skemp, R. (1976). Relational understanding and instrumental understanding. Mathematics Teaching, 77, 20-26.

[25] Teacher Package : Differential Equation. (2007). Plus magazine Retrieved 18.11.2011, 2011, from http://plus.maths.org/content/ teacher-package-differential-equations

[26] Weller, K., Arnon, I., \& Dubinsky, E. (2009). Preservice Teachers' Understanding of the Relation Between a Fraction or Integer and 
Its Decimal Expansion. Canadian Journal of Science, Mathematics and Technology Education, 9(1), 5-28. http://dx.doi.org/ 10.1080/14926150902817381

[27] Weller, K., Clark, J. M., Dubinsky, E., Loch, S., McDonald, M. A., \& Merkovsky, R. R. (2003). Student performance and attitudes in courses based on APOS Theory and the ACE teaching Cycle. In A. Selden (Ed.), Research in collegiate mathematics education (Vol. 5, pp. 97-130): CBMS.

[28] World Bank. (1994). Higher Education - The lessons of experience. Washington D.C: World Bank.

[29] World Bank. (2002). Constructing Knowledge Societies: New challenges for tertiary education. Washington D.C: World Bank.

\section{AUTHOR}

Noraishiyah ABDULLAH, Mrs. is with The University of Manchester, Oxford Road, M13 9PL United Kingdom. (Noraishiyah.abdullah@postgrad.manchester.ac.uk, annaisyah@yahoo.com)

This article is an extended and modified version of a paper presented at the International Conference on Engineering Pedagogy (IGIP2012), held 26 - 28 September 2012, in Villach, Austria. Received 2 January 2013. Published as resubmitted by the authors 27 February 2013. 